\title{
The Intensity of Various Powder Elemental Sulfur Oxidations in the Soda Brackish Soil
}

\author{
Kanaibek Kubenkulov, Askhat Naushabayev, Nurzhamal Khokhanbayeva ${ }^{1}$
}

\begin{abstract}
In the article are considered the matters of reclamation efficiency of elemental sulfur with various dispersion in the sodasaline soils of the plain of the southeast of Kazakhstan.
\end{abstract}

Keywords-brackish soil, alkalinity, sulfur, dispersion, reclamation.

\section{INTRODUCTION}

$\mathrm{T}$ HE saline soils are found in all regions of the Republic of Kazakhstan. If in north, north-west and center regions mostly are dried soils, in south, on the contrary, mostly are saline soils.

The saline soils occupy most territory of Almaty region (2.7 million ha. or $12.2 \%$ ). They are found in a bit, middle, strong and very strong saline soil levels, and take 30,20,37, 13\%, respectively. They spread in the mountains and valleys.

The main measure of reclamation is to wash with water in the artificial drainage system in the saline soils. But, this measure is useless because of low water permeability of soda brackish soils and soda's bad solubility in cool water.

Soda saline dried soils spread in the dark and dark brownish soils, also in the hydromorphic and mid-hydromorphic soils of the southern and south-eastern intro regions. In the last ones the soda saline soils take 7.095 million hectares [1]. Their $18.6 \%$ is situated in Almaty, $47.7 \%$ - in Zhambyl, $27.3 \%$ - in South Kazakhstan and $21.7 \%$ - in Kyzylorda regions. The percentage of good visible dried "B" layers are 19.0, 12.3, 100 and $70.5 \%$, respectively. The spreading of the North Tien Shan's most fertile soils in the meadow, meadow grey, meadow dark brownish soils shows the importance of improving their fertility. Becoming soda saline of this kind of soils was the reason for decreasing of agriculture productivity from $15 \%$ to $45 \%$ [2]. Certainly, in the pastures with soda brackish soils the natural plant got thin, and spots without any plant formed in the ploughed fields. Their territory got tens or hundreds square meters, in some places got even several hectares. The agro measures are made in full in these small and middle spots from spring till harvesting period every year, it means the material, financial and working consumptions are not repaid. The large spots are not usable for ploughing. The above-mentioned cases show the necessity of complicated reclamation measures in the soda brackish soils of irrigated ploughed fields.

At present for reclamation of the soda saline alkaline soils are used traditional gypsum, mainly phosphogypsum technology in the republic. But, its profit is low, because of necessity to use its big volume (15-40 tns/ha), and crystal surfaces are covered with humus clay carbonate [3]. Thereupon, it is necessary to find the economic and ecological profitable technology for reclamation the alkaline saline soils. In our opinion, this ameliorator is the elemental sulfur used in oil gas production as auxiliary product. Its total amount is 8 million tons, and takes second place in the world after Iran. The main reason is that, the sulfur takes $10-18 \%$ of raw oil, and high demand. That is why the utilization of sulfur is so actual [4].

Thus, the above-mentioned circumstances prevailing in our country at the present, notably significantly many alkaline saline soils in areas of agriculture, the bad effectiveness of meliorates used at the present, and the amount of accumulated sulfur polluting environment, require to clarify the reclamation opportunity and to find its technology. Increasing the oxidation of elemental sulfur, in our opinion, can solve this problem. Because sulfur is the element with high inertia. It doesn't oxidize in air, doesn't melt in water, but sulfur oxidizes slow with oxidizing microorganisms in soil. The process of oxidation of sulfur can be significantly accelerate by microbiological method, sulfur oxidant bacteria's active strains with sulfur, or by physical method, sulfur particles under high dispersion, or by making good hydrothermal, aeration conditions and controlling $\mathrm{pH}$ indicators of soil. The dioxide of sulfur formed in soil reacts easily with water, in this way creates the best ameliorant for alkaline soil sulfuric acid. The article presents the research results on this issue.

\section{MATERIALS AND METHODS}

The researches were on the farms of "Amiran Agro" LLP located in Nura rural district, Northern part of Talgar district, Almaty region.

Agro territory borders on stone road Zhetygen-Kyrbaltabay in North, Lep in East, Esik river in West. The territory 1842,4 ha. Fodder is grown for feeding for 650 heads of dairy cows on the farm. They are: corn silage, soybeans, alfalfa, and winter and spring barley and wheat. The showering method is used for irrigation only.

The farm is located in the middle of Ile lowland with simple grey soils and light grey soils. The soda saline soils are prevailing. They differ significantly in creation and structure from regional simple soils, and form spots in space (fig. 1).

\footnotetext{
${ }^{1}$ Kazakh National Agrarian University, Almaty, Kazakhstan
} 


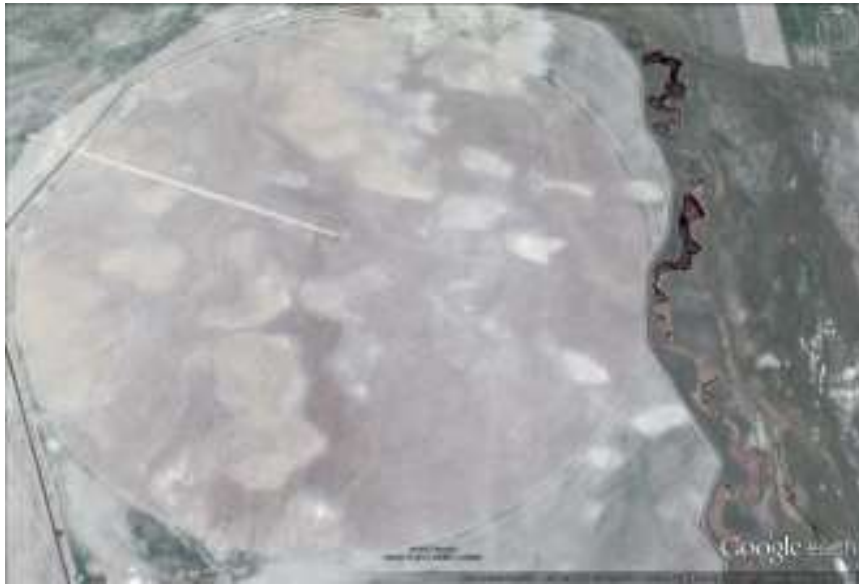

Fig. 1. The 2-nd section of "Amiran Agro" LLP from space view

The experiments were carried out according to well-known methods. In other circumstances when sulfur parts are being crushed, their surface area dramatically increase, with the increasing accessibility to microorganisms active oxidation of sulfur increases, laboratory tests were carried out to determine their connections.

To determine the dependencies between sulfur particles dispersal levels and their oxidation intensity in saline soils used the elemental sulfur with various dispersal powders, and were carried out laboratory tests according to the scheme in the following way:
1. Observation (soil without sulfates)

2. The diameter of the particles of elemental sulfur into the soil is $0.50-0.25 \mathrm{~mm}$ or $500-250$ microns $\left(\mathrm{S}_{1}\right)$;

3 . The diameter of the particles of elemental sulfur into the soil is $0.25-0.10 \mathrm{~mm}$, or $250-100$ microns $\left(\mathrm{S}_{2}\right)$;

4. The diameter of the particles of elemental sulfur into the soil is $40-5$ microns $\left(S_{3}\right)$.

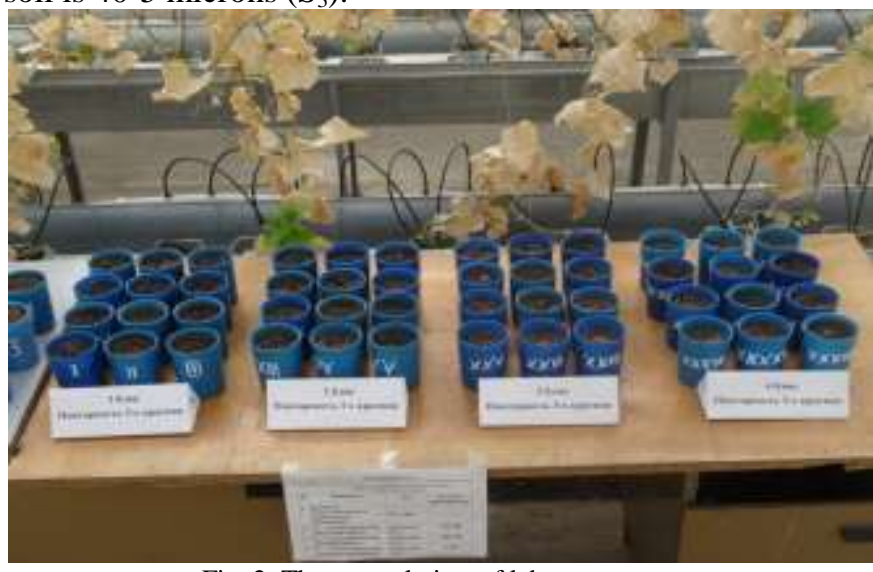

Fig. 2. The general view of laboratory tests

The test was carried out by incubation of sulfur doses (160 $\mathrm{mg}$ per $100 \mathrm{~g}$ of soil) to soda saline partially hydromorphy dried soil for 15,30 , and 90 days.

\section{RESULTS AND DISCUSSION}

TABLE 1 . The influence of incubation of fractions of elemental sulphur with various dispersals in soda saline partially hydromorphy dried soil to filtered water ionic content of soil, salt amount and soil's pH (incubation time 15 days), $\frac{\mathrm{mg}-\mathrm{eq}}{\mathrm{g}}$

\begin{tabular}{|c|c|c|c|c|c|c|c|c|c|}
\hline Test variant & \multicolumn{2}{|c|}{ Alkaline } & $\mathrm{Cl}^{-}$ & $\mathrm{SO}_{4}{ }^{2-}$ & $\mathrm{Ca}^{2+}$ & $\mathrm{Mg}^{2+}$ & $\mathrm{Na}^{+}$ & $\begin{array}{c}\text { Salt amount, } \\
\%\end{array}$ & $\mathrm{pH}$ \\
\hline $\begin{array}{c}\text { Observation } \\
\text { (without sulfur) }\end{array}$ & 2,23 & 0,57 & 0,34 & 3,91 & 0,57 & 0,70 & 5,16 & 0,491 & 8,4 \\
\hline \multirow[t]{2}{*}{$\mathrm{S}_{1}$} & 2,18 & 0,55 & 0,28 & 4,92 & 0,47 & 0,87 & 6,04 & \multirow[b]{2}{*}{0,554} & \multirow[b]{2}{*}{8,4} \\
\hline & 0,133 & 0,017 & 0,010 & 0,436 & 0,009 & 0,010 & 0,139 & & \\
\hline \multirow[t]{2}{*}{$\mathrm{S}_{2}$} & 1,68 & 0,40 & 0,19 & 5,25 & 0,43 & 0,83 & 5,85 & \multirow{2}{*}{0,593} & \multirow{2}{*}{8,3} \\
\hline & 0,102 & 0,012 & 0,007 & 0,252 & 0,009 & 0,010 & 0,135 & & \\
\hline
\end{tabular}

According to the table, the salinization of soil sample taken for testing is soda-sulphate type (table 1). In salt amount $(0.491 \%)$ the share of sodium ions is more priority. That is why, in the liquid phase of the soil the acid salt of sodium (NaHCO3, Na2CO3) is privileged. As the result, the environment of soil is middle alkaline ( $\mathrm{pH} 8.4)$.

Incubation of these various dispersal $(0.50-0.25 \mathrm{~mm}, 0.25$ $0.10 \mathrm{~mm}$, and 5-40 microns) sulfur doses in the alkaline taking in the comfort hydrothermal conditions for two weeks made significant influence to ionic content of filtered water.

This greatly that short-term incubation demonstrated the dependence of elemental sulfur oxidation intensity to dispersion of parts. Sulfur put in soil transforms to di - and trioxide $\left(\mathrm{SO}_{2}^{2-}, \mathrm{SO}_{2}^{2-}\right)$, then it becomes easy to contact with water, forms sulphuric acid, reacts with the liquid and solid soil phases, according to the below diagram (fig 3 ). 
From experience, oxidation intensity of sulfur fractions pushes away from each other. The amount of sulfate ion formed by oxidation of large fractions of elemental sulfur (0.50 to $0.25 \mathrm{~mm})$ is equal $4.92 \mathrm{mEq}$ per $100 \mathrm{~g}$ of soil. According to this test, more for $1.01 \mathrm{mEq}$. Therefore, if $1 \mathrm{mEq}$ $\mathrm{SO}_{4}^{2-}$ is equal to $48 \mathrm{mg}$, as we know, so the amount of sulfate ion formed from added sulfur in $100 \mathrm{~g}$ of soil $(48 \times 1,01)$ is equal to $48.5 \mathrm{mg}$. If take into consideration that, when $32 \mathrm{~g}$ of sulfur oxidases $(32+64), 96 \mathrm{mg}$ of sulfate ions create, i.e. more for three times, so for creating of $48.5 \mathrm{mg} \mathrm{SO}_{4}^{2-}(48,5: 3)$ $16.2 \mathrm{mg}$ of sulfur is needed. As follows, $160 \mathrm{mg}$ of large fractions of elemental sulfur in $100 \mathrm{~g}$ of soil in 15 days only its $10.1 \%$ transformed to oxide form.

The oxidation of the middle fractions of elemental sulfur $(0.25-0.10 \mathrm{~mm})$ is slightly higher than the large ones $(0.50$ $0.25 \mathrm{~mm}$ ). According the test, its amount is more for $1,34 \mathrm{mEq}$ or $(1,34 \times 48) 64,32 \mathrm{mg}$ of formed $\mathrm{SO}_{4}^{2-}$. In these conditions $\mathrm{SO}_{4}^{2-}(64,32: 3)$ creates after oxidation of $21,41 \mathrm{mg}$ of sulfur, it takes $13,4 \%$ of added sulfur.

A high rate of oxidation of sulfur is noted in very small fractions (diameter of particles 5-40 microns). Here, the amount of $\mathrm{SO}_{4}^{2-}$ formed in $100 \mathrm{~g}$ of soil is equal to $8.91 \mathrm{mEq}$. These newly formed $\mathrm{SO}_{4}^{2-}$ ions in terms of $100 \mathrm{~g}$ soil (8.91-
3.91) compile $5.00 \mathrm{mEq}$ or form $(5,00 \times 48) 240 \mathrm{mg}$ of $\mathrm{SO}_{4}^{2-}$. The oxidation intensity of these small size fractions is higher for 4-5 times then the large ones. This amount of $\mathrm{SO}_{4}^{2-}(240: 3)$ forms during the oxidation of $80 \mathrm{mg}$ of sulfur. It shows that $50 \%$ of elemental sulfur applied to soil was oxidized.

In addition to the above, the intensity of oxidation of elemental sulfur in soda saline soil increases in early period of incubation, revealed that in connection with dispersing of particles. The experience of sulfur in alkaline soil as a result of large, middle and small fractions in 15 days of their incubation, respectively, oxidize for $10.1 ; 13.4$ and $50.0 \%$.

The incubation of sulfur fractions for 30 days reduces alkalinity of the filtered water of soil. It is made by reducing of bicarbonate $\left(\mathrm{HCO}_{3}{ }^{-}\right)$, especially the normal carbonate $\left(\mathrm{CO}_{3}{ }^{2-}\right)$ ions. In the making influence of sulfur to reduce the alkalinity of soil the fractions with 5-40 microns are on the top again. The soil environment received the neutral level in this variant (table 2).

TABLE 2. Influence of incubation of fractions of elemental sulphur with various dispersals in soda saline partially hydromorphy dried soil to filtered water ionic content of soil, salt amount and soil's pH (incubation time 30 days), $\frac{\mathrm{mEq}}{\mathrm{gg}}$

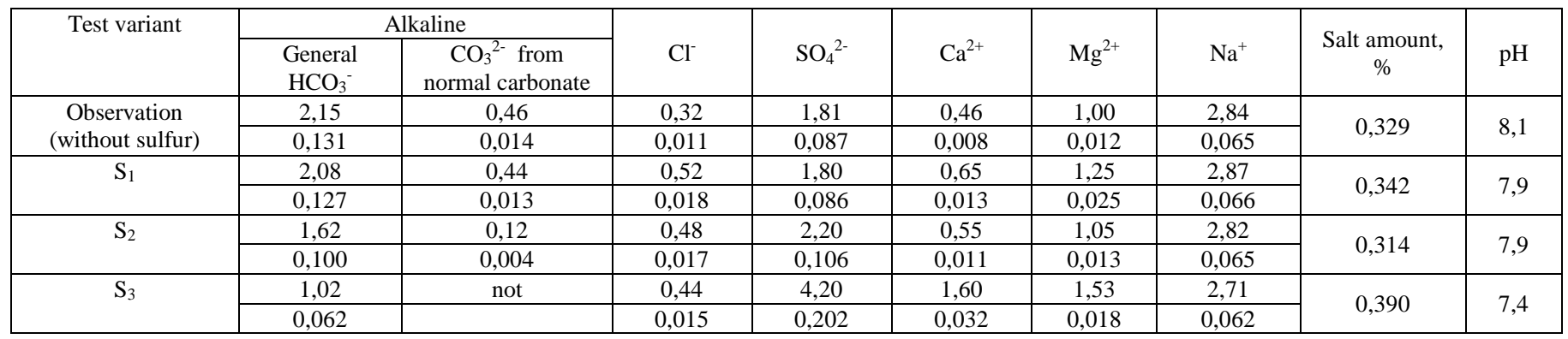

TABLE 3. Influence of incubation of fractions of elemental sulphur with various dispersals in soda saline partially hydromorphy dried soil to filtered water ionic content of soil, salt amount and soil's pH (incubation time 90 days), $\frac{\mathrm{mEq}}{\mathrm{gg}}$

\begin{tabular}{|c|c|c|c|c|c|c|c|c|c|}
\hline Test variant & \multicolumn{2}{|c|}{ Alkaline } & $\mathrm{Cl}^{-}$ & $\mathrm{SO}_{4}{ }^{2-}$ & $\mathrm{Ca}^{2+}$ & $\mathrm{Mg}^{2+}$ & $\mathrm{Na}^{+}$ & $\begin{array}{c}\text { Salt amount, } \\
\%\end{array}$ & $\mathrm{pH}$ \\
\hline $\begin{array}{c}\text { Observation } \\
\text { (without sulfur) }\end{array}$ & 2.07 & traces & 0.32 & 2.17 & 0.917 & 1.17 & 2.81 & 0.280 & 8.1 \\
\hline \multirow[t]{2}{*}{$\mathrm{S}_{1}$} & 1.93 & $"$ & 0.49 & 2.25 & 1.17 & 0.75 & 2.34 & \multirow{2}{*}{0.328} & \multirow{2}{*}{7.8} \\
\hline & 0.117 & & 0.017 & 0.108 & 0.024 & 0.009 & 0.053 & & \\
\hline $\mathrm{S}_{2}$ & 0.89 & $"$ & 0.39 & 5.34 & 1.00 & 0.75 & 4.86 & 0.466 & 7.4 \\
\hline $\mathrm{S}_{3}$ & 0.045 & & 0.012 & 0.328 & 0.028 & 0.014 & 0.123 & 0.552 & 6.9 \\
\hline
\end{tabular}

From the third table according to filtered water and sulfate ions data, we can easily note the dependence of sulfur oxidation intensity given to the soil from sulfur fractions. The most intensive oxidation is in the smallest fractions of sulfur (5-40 microns). The amount of sulfate ions per $100 \mathrm{~g}$ of soil is equal to $6.84 \mathrm{mEq}$. Sulfuric acid formed from the oxidation process of sulfur doesn't just increase sulfate ion quantity, but also makes significant influence to other ion quantity (except chlorine). The increase of dispersal of sulfur particles, decreases the quantity of bicarbonate and normal carbonates sharply, on the contrary, sulphate and sodium ions increase. As a result, the total initial $\left(\mathrm{HCO}_{3}{ }^{-}\right)$alkalinity of soil decreases in three times, sodium carbonate $\left(\mathrm{CO}_{3}{ }^{2-}\right)$ destroys generally, instead of it the neutral salt $\mathrm{Na}_{2} \mathrm{SO}_{4}$ becomes privileged. In these conditions, the alkalinity of soil environment continues 
decreasing, and puts in an acidic environment.

\section{CONCLUSION}

1. In the soda brackish dried soil the oxidation of elemental sulfur appears from the first days of test, but its intensity depends on dispersing of sulfur particles.

2. The large (500-250 microns), middle (250-100 microns) and small (40-5 microns) fractions of elemental sulfur applied to the soil in equal portions (160 mg for $100 \mathrm{~g}$ of soil) after 15 days incubation, oxidize $10.1 ; 13.4$ and $50.0 \%$, respectively, and transform to the perfect ameliorant for the alkaline saline soil - sulphuric acid.

3. The intensive oxidation of sulfur small fractions in incubation period of 30 and 90 days, transformes the sulfate soda middle brackish middle alkaline soil to the sulfate neutral middle brackish soil; it shows the effectiveness of small dispersal sulfur to alkaline soda brackish soils, as ameliorant.

\section{REFERENCES}

[1] Borovski V.M. Geochemical salinize soil of the Kazakhstan, Science, Moscow, 1978, 172p.

[2] R.S. Bespaev, "Melioration Meadow-serozem soils mountain of Ily Alatau", synopsis candidate Agriculture Science, Uzbekistan, Tashkent, 1988, 17p.

[3] I.I. Feofarova, "Psevmorvous calcite by gypsum in the soils", Proceedings of the Soil Institute of the after name of V.Dokuchaev, ch. 34, 1950, pp.202-206.

[4] Contour of the technological development oil gas factory direction in the Kazakhstan. Fase 2. Analyses technological complication. prepare: department project and technology factory Shell, December, 2011, pp.44-47. 